\title{
Inhibition by Adenosine of Aggregation Centre Initiation and Cyclic AMP Binding in Dictyostelium
}

\author{
By PETER C. NEWELL* AND FIONA M. ROSS \\ Department of Biochemistry, University of Oxford, Oxford OXI $3 Q U, U . K$.
}

(Received 21 December 1981; revised 16 March 1982)

\begin{abstract}
The inhibitory action of adenosine on the initiation of aggregation centre formation in starving Dictyostelium discoideum was examined and used to test assumptions of theoretical models of cyclic AMP signalling. Adenosine at $5 \mathrm{~mm}$ strongly inhibited aggregation centre initiation without preventing signal relay. Inosine or AMP at $10 \mathrm{mM}$ had no effect and did not prevent the effect of adenosine. Adenosine had no effect on cellular phosphodiesterase activity, contact site A formation, or chemotaxis to small drops of cyclic AMP. The chemotactically-related responses of rapid cyclic GMP formation and changes in light scattering after pulses of cyclic AMP did not show any inhibition or decrease in sensitivity to the signal in the presence of adenosine. However, binding of ${ }^{3} \mathrm{H}$-labelled cyclic AMP to cell surface receptors was strongly inhibited by adenosine. The maximum inhibition was approximately $90 \%$ and was non-competitive with respect to cyclic AMP. The role of cell surface cyclic AMP receptors in the mechanism of initiation and the implications of the effects of adenosine for the role of cyclic GMP as a secondary messenger are discussed.
\end{abstract}

\section{INTRODUCTION}

During the aggregation phase of the cellular slime mould Dictyostelium, populations of starving amoebae move toward collecting centres and form a multicellular organism. The amoebae are attracted into the centres by pulses of cyclic AMP that are rhythmically emitted by amoebae at the centres (see reviews by Newell, 1977, 1978; Darmon \& Brachet, 1978). Theoretical models have been proposed that account for pulsatile release of cyclic AMP in terms of feed-back loops whose excitability can be raised to the point of autonomous generation of cyclic AMP pulses (Keller \& Segel, 1970; Durston, 1973; Goldbeter \& Erneux, 1978; Goldbeter \& Segel, 1980). In these models it is proposed that the amoebae at the aggregation centres only differ from amoebae in the responding population in having attained an excitability above the threshold for autonomous oscillation. An assumption of the models is that the mechanism of initiation of autonomous cyclic AMP signals is the same as that used for relay of the signals by the responding population and does not require a separate internal oscillator. One way of testing this assumption is to compare the effects of inhibitors on the process of initiation and relay. Because early work by Bradley et al. (1956) reported that adenine decreased the number of centres formed by starving populations on agar surfaces, the effects of adenine and the more soluble nucleoside adenosine were investigated and correlated with changes in components of the signalling system.

\section{METHODS}

Growth media and chemicals. The composition and methods of preparation of nutrient (SM) and the chemicals used were as described previously (Sussman, 1966; Mosses et al., 1975; Ratner \& Newell, 1978). Adenosine, adenine, inosine and AMP were obtained from Sigma. Nylon bolting cloth was a gift from John Stanier, Sherborne St., Manchester, U.K.

KP6 buffers. Potassium phosphate buffer pH 6.0 (KP6) was made up as a $10 \times$ strength solution containing $87.7 \mathrm{ml} 500 \mathrm{~mm}-\mathrm{KH}_{2} \mathrm{PO}_{4}$ and $12.3 \mathrm{ml} 500 \mathrm{~mm}-\mathrm{K}_{2} \mathrm{HPO}_{4}$, and diluted when required. 
KMMP agar for photography of starving populations. KMMP agar was prepared by adding to $960 \mathrm{ml}$ deionized water: $\mathrm{KCl}, 1.0 \mathrm{~g} ; \mathrm{MgCl}_{2}, 0.2 \mathrm{~g} ; \mathrm{MnCl}_{2}, 0.2 \mathrm{~g} ; \mathrm{KP} 6 \times 10,40 \mathrm{ml}$; and Difco Bacto Agar, $10 \mathrm{~g}$. The suspension was gently boiled until the agar had completely dissolved and, after cooling for $10 \mathrm{~min}, 5 \mathrm{ml}$ samples were dispensed into clean $50 \mathrm{~mm}$ Petri dishes resting on a levelled surface. For clear photography it is essential to have thin layers of agar that lack haze from impurities or precipitates caused by autoclaving agar in mixed salts solutions. The plates were stored at $2^{\circ} \mathrm{C}$ and used within 2-3 d of being poured. Adenosine was added to the agar either as solid before boiling or, alternatively, as $5 \mathrm{ml}$ of $2 \times$ strength solution pipetted on top of the agar after pouring and setting. Diffusion into the agar overnight at $2{ }^{\circ} \mathrm{C}$ produced a final concentration of $5 \mathrm{mM}$, the excess fluid being decanted before use.

Growth conditions and maintenance of stocks. Strains of D. discoideum were grown in association with Klebsiella aerogenes strain $\mathrm{OXF} 1$ at $22^{\circ} \mathrm{C}$ in the dark. Stocks were maintained as spores, collected in horse serum, dried on silica gel and stored at $4{ }^{\circ} \mathrm{C}$. The $D$. discoideum strains used for the experiments detailed below were NP187 (Mullens \& Newell, 1978; Wallace \& Newell, 1982) and NP377 (Ross \& Newell, 1979, 1981). Both these strains are developmentally competent. Strain NP377 also bears the streamer mutation stmF that produces wide movement (bright) bands in synchronously developing cultures.

Initiation of starvation. Amoebae were harvested from SM agar plates after approximately $40 \mathrm{~h}$ growth with $K$. aerogenes as food source, washed free of bacteria and resuspended in KP6 at $3 \times 10^{7}$ amoebae $\mathrm{ml}^{-1}$. Samples $(1 \mathrm{ml})$ were dispensed on to KMMP agar plates in $50 \mathrm{~mm}$ dishes, allowed to settle for $30 \mathrm{~min}$, excess liquid was decanted and the plates were air dried for about $20 \mathrm{~min}$ until the layer of amoebae had an even matt appearance. For synchronous development it is important that an even layer of amoebae is deposited over the agar surface, and any loss of amoebae during the decanting stage produces poor quality images under dark-field optics.

Assay for binding of cyclic AMP. The assay used was that of Green \& Newell (1975), except that Nuclepore polycarbonate filters were used instead of Millipore membrane filters (Mullens \& Newell, 1978).

Light scattering in cell suspensions. Measurements of light scattering changes were made following the method of Gerisch \& Hess (1974) as described by Glazer \& Newell (1981).

Contact sites A. Assay for formation of contact sites A was carried out as described by Glazer \& Newell (1981).

Test for chemotaxis. Chemotactic assays were performed by adding drops $(10 \mu \mathrm{l})$ of starving washed amoebae ( 5 $\left.\times 10^{8} \mathrm{ml}^{-1}\right)$ to the surface of $50 \mathrm{~mm}$ agar plates $[2.5 \mathrm{ml} \mathrm{l} \%(\mathrm{w} / \mathrm{v})$ Oxoid purified agar dissolved in deionized water by boiling] and placing drops $(10 \mu \mathrm{l})$ of cyclic AMP $(100 \mu \mathrm{M}-10 \mathrm{mM})$ on the agar beside the drop of amoebae at a distance of $3 \mathrm{~mm}$. As controls, drops $(10 \mu \mathrm{l})$ of sterile deionized water were added to the agar $3 \mathrm{~mm}$ away from the drop of amoebae on the far side from the cyclic AMP. If chemotaxis occurred, the amoebae moved radially from their original site, in the form of an easily observed crescent-shaped ridge in the direction of the cyclic AMP drop, within $16 \mathrm{~h}$ of deposition.

Phosphodiesterase assay. This was done as described by Ross \& Newell (1981), except that the cells were starved in shaken suspension at $23^{\circ} \mathrm{C}$ in $17 \mathrm{mM}-\mathrm{K}^{+} / \mathrm{Na}^{+}$phosphate buffer $\mathrm{pH} 6 \cdot 15$, at a cell density of $2 \times 10^{7} \mathrm{ml}^{-1}$.

Cyclic GMP assays. These were done as described by Ross \& Newell (1981).

Wedge agar technique. Gradients of adenosine in agar plates were made by pouring a layer of adenosine-containing agar into $50 \mathrm{~mm}$ Petri dishes that were held on a slope and then adding a top layer of KMMP agar without adenosine. Diffusion of the adenosine through the agar produced a gradient of this compound running from approximately 0 to $5 \mathrm{mM}$. The bottom wedge layer $(4 \mathrm{ml})$ consisted of $2 \mathrm{ml} \mathrm{KMMP}$ agar diluted immediately before pouring with $2 \mathrm{ml} 10 \mathrm{mM}$-adenosine. The top layer was $5 \mathrm{ml} \mathrm{KMMP}$ agar.

Photography. A high-sensitivity, dark-field optical system was built based on the design of Trevan (Gross et al., 1976). Details of the optical components involved were given by Ross \& Newell (1981).

\section{RESULTS}

\section{Initiation of aggregation centres in the presence of adenosine}

The effect of adenosine on the rate of initiation was first studied using a gradient of adenosine set up in non-nutrient agar plates (see Methods). When $3 \times 10^{7}$ starving washed amoebae of the developmentally competent strains NP187 or NP377 were allowed to develop on the surface of the adenosine wedge plates, the pattern of aggregation centres formed was as shown in Fig. 1. The side of the dish containing up to $5 \mathrm{~mm}$-adenosine showed relatively few aggregation centres compared to the side with smaller amounts of adenosine, although signal relay was apparently unaffected. As a consequence of this differential inhibition of centre initiation compared to signal relay, the territory sizes and the aggregates formed on the high adenosine side of the plate were very much larger than on the side without adenosine. Similar production of large territories throughout the plate could be observed if adenosine (or adenine) were added (or allowed to soak 

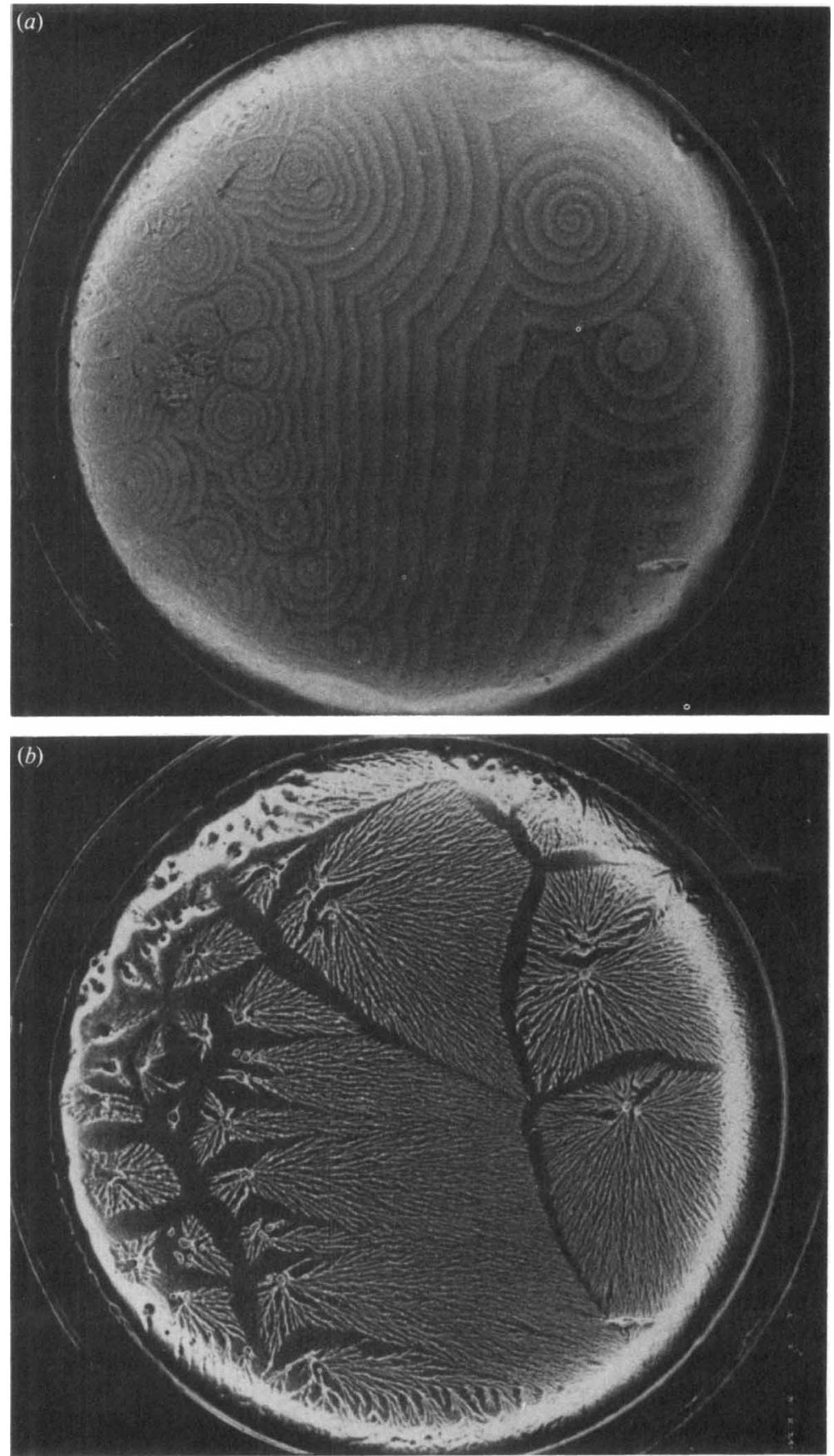

Fig. 1. Effect of adenosine on frequency of initiation of aggregation centres in Dictyostelium discoideum seen using the agar wedge technique. Amoebae were allowed to develop on KMMP agar over a gradient of adenosine $(0-5 \mathrm{mM})$, the highest concentration being on the right. The photographs of whole $50 \mathrm{~mm}$ Petri dishes, taken with dark-field optics, show the pattern of signal waves formed $1 \mathrm{~h}$ after transfer from $7{ }^{\circ} \mathrm{C}$ to $22^{\circ} \mathrm{C}(a)$ and the same field now forming streams $1.5 \mathrm{~h}$ later $(b)$. 
in overnight) to produce a uniform final concentration of $5 \mathrm{mM}$ in the agar. Increasing the concentration of adenosine to 10 to $15 \mathrm{~mm}$ did not increase the inhibitory effect.

If, instead of allowing development of starving amoebae in the presence of adenosine for several hours, the cells were allowed to develop on normal KMMP agar plates up to the point where centre initiation was just starting and then adenosine was sprayed on to the plate, it was found that further centre initiation was inhibited and, within 15-20 min, the establishment of what later became large territories could be observed. Clearly the inhibitory action of adenosine is rapid and must be acting on some component that is present at the time of adenosine addition rather than on the formation of that component.

Sometimes it was found that initiation centres that were actively signalling in the presence of $5 \mathrm{mM}$-adenosine could fail if additional stress such as a move from darkness to strongly illuminated conditions was made (Fig. 2). The cells in these territories were clearly still capable of signal relay, as the signals of neighbouring centres could be seen to be propagated inwards from the edge of the territories. After an interval, initiation of signalling sometimes restarted in the failed territories, although by this time many of the amoebae had been irrevocably drawn into the influence of the more advanced territories nearby.

The specificity of the effect of adenosine on initiation was demonstrated by testing the effects of other similar compounds. Studies using inosine, AMP and histidine revealed no inhibition of the rate of initiation when these compounds were added to the agar to a final concentration of $10 \mathrm{~mm}$ and no diminution of the inhibition by adenosine was noted when these compounds were used in conjunction with $5 \mathrm{~mm}$-adenosine.

\section{Mechanism of adenosine inhibition of centre initiation}

In order to establish the mode of action of adenosine, the development of various abilities concerned with aggregation was monitored in the presence and absence of this inhibitor.

Activity of phosphodiesterase in the presence of adenosine. One of the components in the signalling mechanism that has an essential role in the models of cell excitability is the phosphodiesterase enzyme system for destruction of the cyclic AMP signals. The membrane-bound enzyme activity is measurable in washed whole cells, while the extracellular form of the enzyme may be assayed in the supernatant. Assay of phosphodiesterase activity from amoebae of strain NP187 that had developed in liquid for 10-12 h showed that the addition of $5 \mathrm{~mm}$-adenosine had no inhibitory effect on cell-bound enzyme. The effect on extracellular phosphodiesterase appeared to be somewhat variable, but inhibition did not exceed $20 \%$.

Formation of contact sites $A$ in the presence of adenosine. One of the consequences of pulsatile signalling in starving amoebae is the formation of glycoprotein 'contact sites A' that are concerned with the adhesion of cells towards the end of the aggregation phase (Beug et al., 1973; Gerisch et al., 1975). It has been found with aggregation-defective mutants that the inability to produce or relay pulsatile cyclic AMP signals inhibits formation of contact sites A, unless exogenous cyclic AMP pulses are provided (Darmon et al., 1977; Glazer \& Newell, 1981). When starving amoebae of the aggregation-competent strain NP187 were shaken in KP6 buffer, either with our without $5 \mathrm{mM}$-adenosine, and tested periodically for the formation of contact sites $\mathrm{A}$, no difference was detectable, adenosine apparently having no inhibitory effect on their formation.

Chemotaxis in the presence of adenosine. Chemotactic ability in response to cyclic AMP was investigated in three ways. In the first method, drops of cells were placed on agar surfaces close to drops of cyclic AMP of various concentrations from $100 \mu \mathrm{M}-10 \mathrm{mM}$ and the ability of the amoebae to move towards the cyclic AMP was observed. The presence of adenosine at $5 \mathrm{~mm}$ in the agar had no effect on the ability of cells of strain NP187 or NP377 to respond to the chemotactic signals. The second test used the effect of cyclic AMP to cause characteristic changes in the light scattering of starving amoebae held in oxygenated suspension in spectrophotometer cuvettes (Gerisch \& Hess, 1974). These responses have been correlated with chemotactic responses (Ross \& Newell, 1981). With added pulses of cyclic AMP ranging from $0.1 \mathrm{nM}$ to $1 \mu \mathrm{M}$ (final concentration) in the cuvettes, the responses observed for NP187 in the presence of $5 \mathrm{mM}$ adenosine were indistinguishable from those of the control without adenosine, showing that the sensitivity to cyclic AMP signals, as measured by the chemotactic response, is not impaired by 

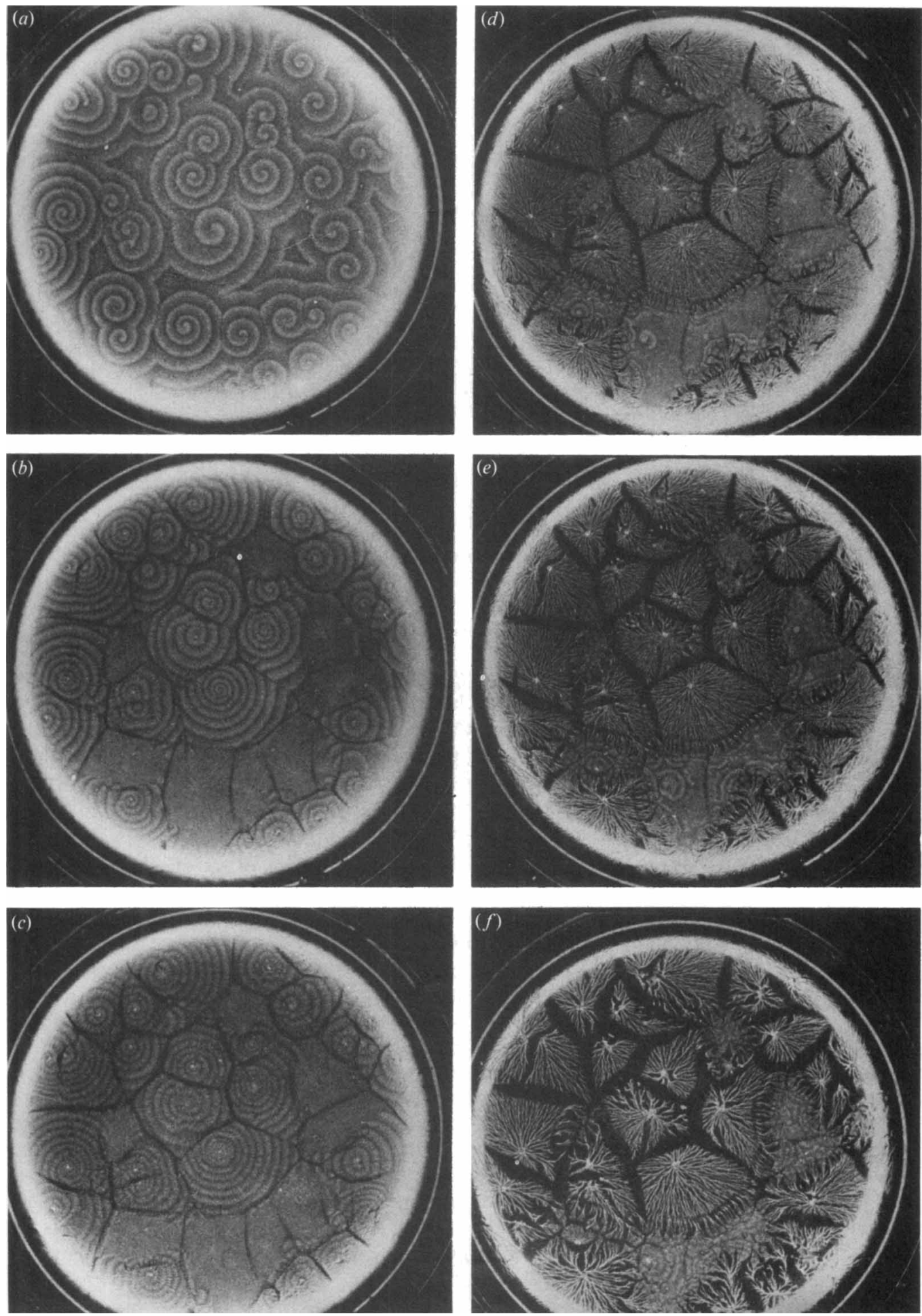

Fig. 2. Pulsatile signalling of starving $D$. discoideum on KMMP agar containing 5 mM-adenosine, showing sudden signalling failure in certain of the fields. $(a-f)$ Time-lapse photographs of the same $50 \mathrm{~mm}$ Petri dish taken at $30 \mathrm{~min}$ intervals using $35 \mathrm{~mm}$ dark-field optics; (c) encroachment by neighbouring fields; $(d)$ recommencement of signalling in one of the failed fields. 


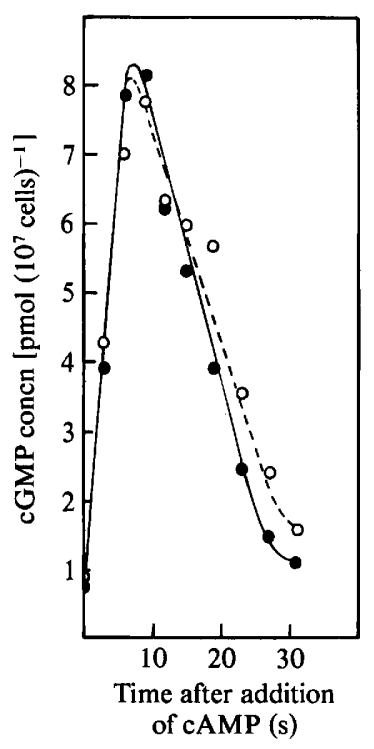

Fig. 3

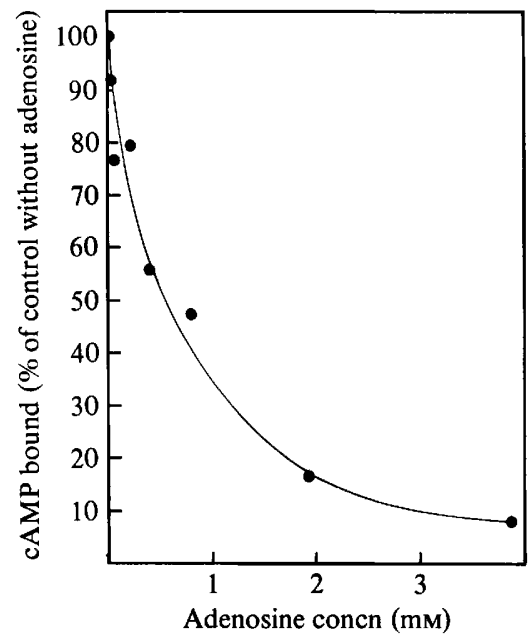

Fig. 4

Fig. 3. Formation of cyclic GMP (cGMP) in response to a pulse of cyclic AMP (cAMP) in the presence $(\mathrm{O})$, and absence $(O)$ of $5 \mathrm{mM}$-adenosine.

Fig. 4. Inhibition of cAMP binding by adenosine. Binding of ${ }^{3} \mathrm{H}$-labelled cAMP to whole cells was measured by filter assay in the presence of adenosine at concentrations of $0-5 \mathrm{mM}$.

the presence of adenosine. The third test measured the brief pulse of cyclic GMP that is transiently formed in response to a pulse of cyclic AMP and which has been implicated in the chemotactic response to cyclic AMP and folate (Mato et al., 1977 a, $b$; Wurster et al., 1977; Mato \& Malchow, 1978; Ross \& Newell, 1981). When strain NP187 was allowed to develop in shaken suspension culture for $8 \mathrm{~h}$ and then tested for the ability to produce cyclic GMP in response to a $50 \mathrm{nM}$ pulse of cyclic AMP in the presence or absence of $5 \mathrm{mM}$ adenosine, it was found that adenosine had no significant effect on either the rate or extent of cyclic GMP formation (Fig. 3).

Inhibition of cyclic AMP binding by adenosine. In contrast to the lack of any effect of adenosine on the aggregation abilities described above, the inhibitory effect of cyclic AMP binding to whole cells was dramatic. When the binding of ${ }^{3} \mathrm{H}$-labelled cyclic AMP by aggregating amoebae was measured in the presence of various concentrations of adenosine, using the filter assay, it was found that binding was progressively diminished as the adenosine concentration was raised to $5 \mathrm{~mm}$ (Fig. 4). Maximal inhibition was approximately $90 \%$, and this value was not significantly increased with adenosine concentrations of $10 \mathrm{mM}$. As $5 \mathrm{~mm}$-adenosine does not inhibit aggregation or signal relay on KMMP agar plates, the inhibition of cyclic AMP receptor binding by $90 \%$ at this adenosine concentration was surprising. To check that the agar did not in some way partially inactivate the adenosine, the extent of inhibition of cyclic AMP receptors was ascertained using a sample of adenosine that had been extracted from a KMMP agar plate containing $10 \mathrm{~mm}$-adenosine by centrifugation of the agar in sachets of nylon bolting cloth. However, no difference in activity was found compared to the untreated adenosine, indicating that there is no reduction of the adenosine inhibition by some factor from the agar.

When the binding of cyclic AMP, over the range 2-400 nM, to amoebae in the absence of adenosine was determined and plotted by the method of Scatchard (1949), a curvilinear plot was obtained as observed previously (Green \& Newell, 1975) (Fig. 5). (In some cases, as in Fig. 5, the curve also showed a downward curvature at very low cyclic AMP concentrations, which is possibly indicative of positive cooperativity as recently reported by Coukell \& Chan, 1980.) When the residual binding of cyclic AMP from 2 to $400 \mathrm{nM}$ was measured in the presence of $5 \mathrm{~mm}$-adenosine and plotted in this way, a small but similarly-shaped curve was produced (Fig. 5). Although the number of receptors present was obviously small, both low- and high-affinity 


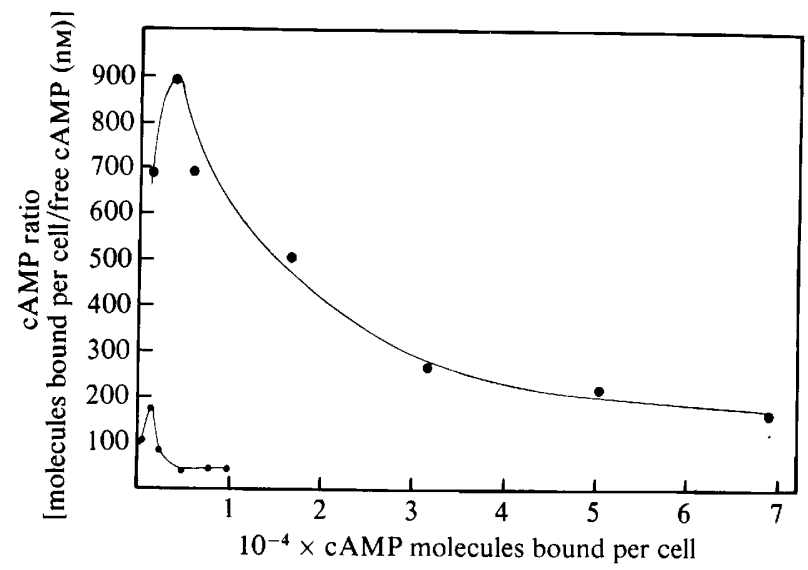

Fig. 5. Scatchard plots of cyclic AMP (cAMP) binding (2-400 nM) in the presence (lower curve) and absence (upper curve) of adenosine at a concentration $(5 \mathrm{mM})$ giving maximal inhibition.

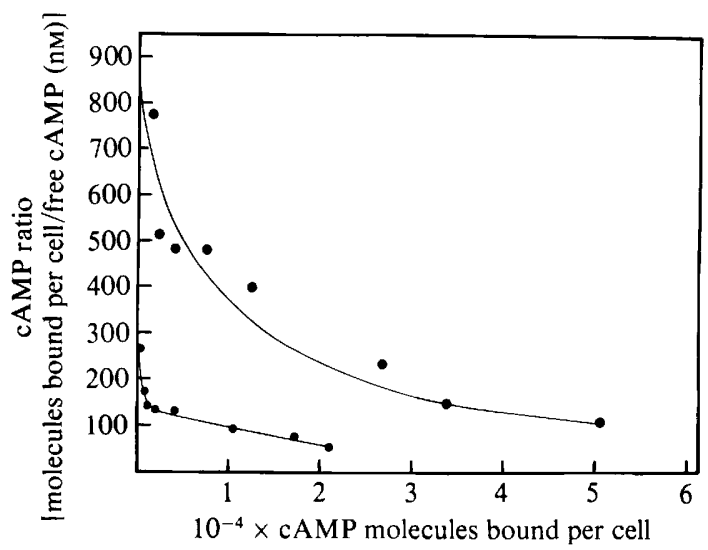

Fig. 6. Scatchard plot of cyclic AMP (cAMP) binding (2-400 nM) in the presence (lower curve) and absence (upper curve) of adenosine at a concentration $(770 \mu \mathrm{M})$ giving approximately $60 \%$ inhibition.

forms were noticeable with affinities of a similar magnitude to the controls. When the inhibition by adenosine (expressed as a percentage of the control value) is calculated for cyclic AMP binding over the range $2-400 \mathrm{nM}$, it is constant at approximately $90 \%$. This suggests that the effect of adenosine is non-competitive with respect to cyclic AMP. However, since it was conceivable that the residual binding was due to a distinct class of receptors that were unaffected by adenosine, the effects of adenosine over the same range of cyclic AMP were investigated using a concentration of adenosine $(770 \mu \mathrm{M})$ that caused only $60 \%$ inhibition. The Scatchard plots produced were again of similar shape (Fig. 6); in this particular experiment no sign of positive cooperativity was detected. When the percentage inhibition was calculated, it was found that adenosine produced approximately $60 \%$ inhibition with cyclic AMP over the range $2-400 \mathrm{nM}$, again indicating that the effect of adenosine was non-competitive. This result was confirmed by examining the data from Fig. 6 using double reciprocal plots of binding against cyclic AMP concentration; binding plots between 50 and $400 \mathrm{nM}$ in the presence or absence of adenosine were found to intercept at the abscissa as expected for non-competitive inhibition.

\section{DISCUSSION}

Adenosine at a concentation of $5 \mathrm{mM}$ inhibited the binding of cyclic AMP to specific cell surface receptors by $90 \%$. The structural similarity of adenosine and cyclic AMP initially 
suggested that adenosine might be competing with cyclic AMP. However, this study suggests that adenosine does not compete with cyclic AMP in this way. Firstly, the extent of inhibition of adenosine on centre initiation seen by dark-field observations is never complete, but is no greater at 10 or $15 \mathrm{~mm}$ than at $5 \mathrm{mM}$. Secondly, the extent of inhibition of binding of cyclic AMP to the cell surface cyclic AMP receptors in the presence of $5 \mathrm{mM}$-adenosine is independent of the cyclic AMP concentration over the range $2-400 \mathrm{nM}$. The same result is found for non-saturating concentrations of adenosine, indicating that the non-competitive nature of the inhibition is not due to a small percentage of receptors unaffected by adenosine. It would thus seem likely that adenosine acts indirectly by binding to receptor molecules other than the cyclic AMP receptors. This conclusion is supported by another study demonstrating rapid, reversible binding of ${ }^{3} \mathrm{H}$ labelled adenosine to adenosine-specific cell surface receptors present at $7 \times 10^{6}$ molecules per cell (Newell, 1982). The lack of any effect on the activity of the cell-bound phosphodiesterase enzyme indicates that these adenosine receptors are not the active sites of the plasma membrane-bound phosphodiesterase. The correlation of inhibition of signal initiation by adenosine with inhibition of the cell surface receptors supports the involvement of these receptors in the initiation process and thereby supports one of the assumptions inherent in instability models of cell signalling based on cell excitability. If the periodic signal pulses had been generated by an internal oscillator rather than by the excitable feedback loop used for signal relay, no effect on initiation by adenosine would have been expected, as the cyclic AMP receptors would not have been part of the oscillation mechanism.

Relay was clearly not prevented by adenosine (as may be observed by the propagation of signal waves shown in Figs 1 and 2), even under conditions that inhibited $90 \%$ of the surface cyclic AMP receptors. Moreover, from unpublished experiments using amoebae that were relaying signals in the presence or absence of adenosine, the velocity of signal relay (measured from time-lapse photographs) was found to be the same in the presence of $5 \mathrm{~mm}$-adenosine as in its absence. The differential effect of adenosine on initiation rather than relay may be understood by reference to the theoretical studies on the instability model of Golbeter \& Segal (1980). If inhibition of the cyclic AMP receptors lowered the responsiveness of adenylate cyclase to incoming cyclic AMP signals, the state of excitability of the system could be changed, in their terminology (see their Fig. 1), from state $C$ (which allows autonomous signal generation) to state B (which allows only relay of signals). Although the relationship between the number of active cyclic AMP receptors and the relay response is unknown, the finding that spiralling fields of aggregating amoebae are subject to occasional failure in the presence of adenosine when additional stress is supplied (Fig. 2) argues in favour of the sensitivity of the relay response being decreased by adenosine. [Signalling centres initially form signal pulses that are relayed concentrically, the frequency being determined by the autonomously oscillating centre. Spiral wave patterns are produced by breakage of concentric waves and propagation by further signal relay of two contra-rotating signal sources. Such signalling fields do not depend on further autonomous signal generation (Durston, 1973), but are self-generating simply using signal relay.] Quantitative assessment of the sensitivity of the adenylate cyclase enzyme used in the relay response was beyond the scope of the present study but should be feasible using the perfusion and 'signal clamping' techniques of Devreotes et al. (1979).

In view of the powerful inhibitory effect on the surface cyclic AMP receptors, it was surprising that adenosine did not affect chemotaxis or the measurable changes associated with the chemotactic response. Neither in the change in light scattering, nor in the production of cyclic GMP in response to nanomolar concentrations of cyclic AMP, were cells in the presence of adenosine apparently less responsive than the controls to the incoming cyclic AMP signals. The effect on the cyclic GMP response was particularly unexpected, since the production of cyclic GMP is known to be proportional to the concentration of the cyclic AMP signal and the $50 \mathrm{nM}-$ cyclic AMP signal dose used was not at either extreme of the response curve. Clearly, only $10 \%$ of the normal cyclic AMP receptor activity is essential for the chemotactic response. Two explanations seem plausible for this result. Either the cyclic AMP receptors used for chemotaxis are a special minority subset that are adenosine-insensitive, or only a small number of receptors are required for maximal response, the response being dependent on the quality of the cyclic 
AMP binding (fractional occupancy or rate of binding) rather than on the number of receptors involved. The distinction between these two explanations must await more detailed knowledge of the mechanism of receptor action.

A further deduction that may be made from these studies concerns the nature of the linking system or 'second messenger' that connects the cell surface cyclic AMP receptors with the adenylate cyclase used for initiation and relay. The inhibition of initiation by adenosine under conditions where the cyclic GMP response is unaffected suggests that the feed-back loop involving the cyclic AMP receptors and adenylate cyclase may involve a second messenger other than cyclic GMP.

We wish to thank Jane Hardwicke and Steven McClue for technical assistance, Frank Caddick for drawing the figures and for his tireless efforts with the photographic developing and printing, Julian Gross and David Trevan for their advice, Jeannie Wallace for her helpful comments and the SERC for financial assistance.

\section{REFERENCES}

Beug, H., Katz, F. E. \& Gerisch, G. (1973). Dynamics of antigen membrane sites relating to cell aggregation in Dictyostelium discoideum. Journal of Cell Biology 56, 647-658.

Bradley, S. G., Sussman, M. \& ENNIS, H. L. (1956). Environmental factors affecting the aggregation of the cellular slime mold Dictyostelium discoideum. Journal of Protozoology 3, 33-38.

Coukell, M. B. \& Chan, F. K. (1980). Precocious appearence and activation of an adenylate cyclase in a rapid developing mutant of Dictyostelium discoideum. FEBS Letters 110, 39-42.

Darmon, M. \& Brachet, P. (1978). Chemotaxis and differentiation during aggregation of Dictyostelium discoideum amoebae. In Receptors and Recognition, vol. B5, Taxis and Behaviour, pp. 101-139. Edited by G. L. Hazelbauer. London: Chapman \& Hall.

Darmon, M., Barrand, P., Brachet, P., Klein, C. \& Pereira DA Silva, L. (1977). Phenotypic suppression of morphogenetic mutants of Dictyostelium discoideum. Developmental Biology 58, 124-184.

Devreotes, P. N., Derstine, P. L. \& Steck, T. L. (1979). Cyclic 3',5'-AMP in Dictyostelium discoideum. Journal of Cell Biology 80, 291-299.

Durston, A. J. (1973). Dictyostelium discoideum aggregation fields as excitable media. Journal of Theoretical Biology 42, 483-504.

Gerisch, G. \& Hess, B. (1974). Cyclic AMP controlled oscillations in suspended Dictyostelium cells. Their relation to morphogenetic cell interaction. Proceedings of the National Academy of Sciences of the United States of America 71, 2118-2122.

Gerisch, G., Fromm, H., Huesgen, A. \& Wick, U. (1975). Control of cell-contact sites by cyclic AMP pulses in differentiating Dictyostelium cells. Nature, London 255, 547-549.

Glazer, P. M. \& Newell, P. C. (1981). Initiation of aggregation by Dictyostelium discoideum in mutant populations lacking pulsatile signalling. Journal of General Microbiology 125, 221-232.

Goldbeter, A. \& ERNEAUX, T. (1978). Excitability in adenylate-cyclase reaction in Dictyostelium discoideum. FEBS Letters 89, 237-241.

Goldbeter, A. \& SEgel, L. A. (1980). Control of developmental transitions in the cyclic AMP signalling system of Dictyostelium discoideum. Differentiation 17, 127-135.
Green, A. A. \& Newell, P. C. (1975). Evidence for the existence of two types of cyclic AMP binding sites in aggregating cells of Dictyostelium discoideum. Cell 6, 129-136.

Gross, J. D., Peacey, M. J. \& Trevan, D. J. (1976). Signal emission and signal propagation during early aggregation in Dictyostelium discoideum. Journal of Cell Science 22, 645-656.

KelleR, E. R. \& SEGEL, L. A. (1970). Initiation of slime mold aggregation viewed as an instability. Journal of Theoretical Biology 26, 399-415.

Mato, J. M. \& Malchow, D. (1978). Guanylate cyclase activation in response to chemotactic stimulation in Dictyostelium discoideum. FEBS Letters 90 , 119-122.

Mato, J. M., van Haastert, P. J., Krens, F. A., Rhijnsburger, E. H., DobBe, F. C. P. M. \& KoniJN, T. M. $(1977 a)$. Cyclic AMP and folic acid mediated cyclic GMP accumulation in Dictyostelium discoideum. FEBS Letters 79, 331-336.

Mato, J. M., Krens, F. A., van HaAstert, P. J. \& KoniJn, T. M. (1977b). Unified control of chemotaxis and cyclic AMP-mediated cyclic GMP accumulation by cyclic AMP in Dictyostelium discoideum. Biochemical and Biophysical Research Communications 77, 399-402.

Mosses, D., Williams, K. L. \& Newell, P. C. (1975). The use of mitotic crossing-over for genetic analysis in Dictyostelium discoideum: mapping of linkage group II. Journal of General Microbiology 90, 247259.

Mullens, I. A. \& Newell, P. C. (1978). Cyclic AMP binding to cell surface receptors of Dictyostelium. Differentiation 10, 171-176.

NeWELL, P. C. (1977). Aggregation and cell surface receptors in cellular slime moulds. In Receptors and Recognition, vol. B3, Microbial Interactions, pp. 157. Edited by J. L. Reissig. London: Chapman \& Hall.

Newell, P. C. (1978). Cellular communication during aggregation of Dictyostelium. Journal of General Microbiology 104, 1-13.

Newell, P. C. (1982). Cell surface binding of adenosine to Dictyostelium discoideum and inhibition of pulsatile signalling. FEMS Microbiology Letters 13, 417-421.

RATNER, D. I. \& Newell, P. C. (1978). Linkage analy- 
sis in Dictyostelium discoideum using multiply marked tester strains: establishment of linkage group VII and the reassessment of earlier linkage data. Journal of General Microbiology 109, 225-236.

Ross, F. M. \& Newell, P. C. (1979). Genetics of aggregation pattern mutations in the cellular slime mould Dictyostelium discoideum. Journal of General Microbiology 115, 289-300.

Ross, F. M. \& Newell, P. C. (1981). Streamers: chemotactic mutants of Dictyostelium discoideum with altered cyclic GMP metabolism. Journal of General Microbiology 127, 339-350.

SCATCHARD, G. (1949). The attractions of proteins for small molecules and ions. Annals of the New York Academy of Sciences 51, 660-672.

Sussman, M. (1966). Biochemical and genetic methods in the study of cellular slime mold development. Methods in Cell Physiology 2, 397-410.

Wallace, J. S. \& NewEll, P. C. (1982). Genetic analysis by mitotic recombination in Dictyostelium discoideum of growth and developmental loci on linkage group VII. Journal of General Microbiology 128, 953964.

WURSTER, B., SCHUBIGER, K., Wick, U. \& GerisCh, G. (1977). Cyclic GMP in Dictyostelium discoideum, oscillations and pulses in response to folic acid and cyclic AMP signals. FEBS Letters 76, 141-144. 